\title{
Asymmetric Coplanar F-strip Fed Antenna for Dual Band Wireless Applications
}

\author{
Ansal K A, T Shanmuganantham \\ Departement of Electronics Engineering, School of Engineering and Technology \\ Pondycherry Central University
}

\begin{tabular}{l} 
Article Info \\
\hline Article history: \\
Received Oct 12, 2014 \\
Revised Nov 25, 2014 \\
Accepted Dec 20, 2014 \\
\hline Keyword: \\
Asymmetric Coplanar Strips \\
Coplanar Waveguide (CPW) \\
Defected ground structure \\
Dual Band antennas \\
Radiation Pattern
\end{tabular}

\begin{abstract}
A compact planar antenna for dual band applications is presented in this paper. The proposed antenna has Dumbbell shaped defect on the ground plane and it is fed by asymmetric coplanar strip (ACS). The antenna is printed on FR4 epoxy substrate and it has a compact size of $21 \times 19 \times 1.6$ $\mathrm{mm}^{3}$. The antenna exhibits a dual band of resonances at $3.4 \mathrm{GHz}$ and $5.5 \mathrm{GHz}$ which is used for WiMAX/WLAN/HYPERLAN-2/RFID. The planar design, simple feeding techniques and compactness make it easy for the integration of the antenna into circuit boards. Details of the antenna design and simulated results are presented and discussed. Simulation tool, based on the method of moments (Mentor Graphics IE3D version 15.10) has been used to analyze and optimize the antenna. Various features such as compactness, simple configuration and low fabrication cost make the antenna is suitable for dual band wireless applications.
\end{abstract}

Copyright (C) 2015 Institute of Advanced Engineering and Science. All rights reserved.

\section{Corresponding Author:}

Ansal K A,

Departement of Electronics Engineering,

Pondycherry central University,

Puducherry,605014, India

Email: ansal.555@gmail.com

\section{INTRODUCTION}

The rapid growth of wireless internet for high data rate communication has fostered tremendous attention towards the design of compact WLAN antennas. Different types of designs catering to various user requirements have been reported in literature [1-11]. These designs, however, have complex structures which make them difficult to integrate with WLAN systems. Planar antennas have the advantage of easy integration with active circuits. Many types of planar antennas have been reported in the literature. A planar monopole antenna with shorted inverted-L wire proposed [2]. A dual band planar antenna for laptop PC applications is presented [3]. ACS fed antenna with U-shaped open stub for WLAN/WiMAX application proposed in [4]. A CPW fed antenna with asymmetrical ground plane for bandwidth enhancement proposed [5]. ACS antenna for dual band application proposed [6-9]. However these geometries are planar in nature, but larger in dimension than our current proposal. Mentor Graphics IE3D electromagnetic solver is used for the simulation and analysis of the structure. The resulting antenna operates on dual band frequencies of $3.4 / 5.5 \mathrm{GHz}$ and which meets the requirements of WiMAX / WLAN/HIPERLAN-2/RFID applications.

In literatures [10, 11] proposed a fractal antenna for RFID applications, these designs also need rigorous itration to achive the diserd band of resonance. Hence In this article, a planar ACS fed configuration obtained by removing the ground plane at the left of CPW fed antenna which produce a dual band resonance. Some CPW fed designs occupy a little bit more area, so it's difficult for integration. So here, we propose a planar monopole antenna with defected ground structure (DGS) for wireless application with a compact size composed of a ground plane and a vertical F shaped exciting stub, which give two operating bands at 3.4 and $5.5 \mathrm{GHz}$. Details of the proposed antenna design and results are presented. Here dumbbell shaped cascaded 
defect on a lateral ground plane which helps to produce resonance at two different frequency bands. DGS [12] is an etched periodic or non-periodic cascaded configuration which located in the ground plane of planar transmission lines, defect in ground of a planar transmission line (e.g., microstrip, coplanar and conductor backed coplanar waveguide) which disturbs the shield current distribution in the ground plane causes resonance. This disturbance will change the characteristics of a transmission line such as line capacitance and inductance. In effect, any defect etched in the ground plane of the palanar transmission line can give rise to increasing effective capacitance and inductance.

The feeding mechanism of an antenna is a critical factor as far as the compactness is concerned. Normally the feed structure consumes much of the overall antenna dimension. In this antenna design a compact and effective feeding technique is employed. The asymmetric coplanar strip [13-16] feed used here has all the advantages of a uniplanar feed along with compactness. This feeding mechanism is analogous to the CPW feed except that the ACS feed has a single lateral ground strip compared to the twin lateral ground strips in the CPW feed. The characteristic impedance of ACS fed transmission line is calculated by the equation 2 .

\section{GEOMETRY AND DESIGN METHEDOLOGY}

The geometry of the antenna is shown in Figure 1. The antenna is printed on an FR4 dielectric substrate with dielectric constant $\varepsilon_{\mathrm{r}}=4.4$ and loss tangent tan $\delta=0.02$. The antenna has a compact size of $21 \times 19 \times 1.6 \mathrm{~mm}^{3}$. The antenna is fed by Asymmetric coplanar F-strip with the thickness $\mathrm{h}=1.6 \mathrm{~mm}$. The gap ' $\mathrm{g}$ ' between the center conductor and ground planes of proposed ACS fed antenna is $0.35 \mathrm{~mm}$. The ACS feed has $50 \Omega$ characteristic impedance and it is terminated by sub miniature version A (SMA) connector. Since the exciting patch and feed structure are constructed on the same plane, only one metallic layer is present which is in co plane. Hence, the antenna can be easily fabricated with low cost. The antenna has a novel tuning stub of F shape and dumbbell shaped defect on the lateral ground plane. The antenna is simulated and optimized with IE3D electromagnetic solver.

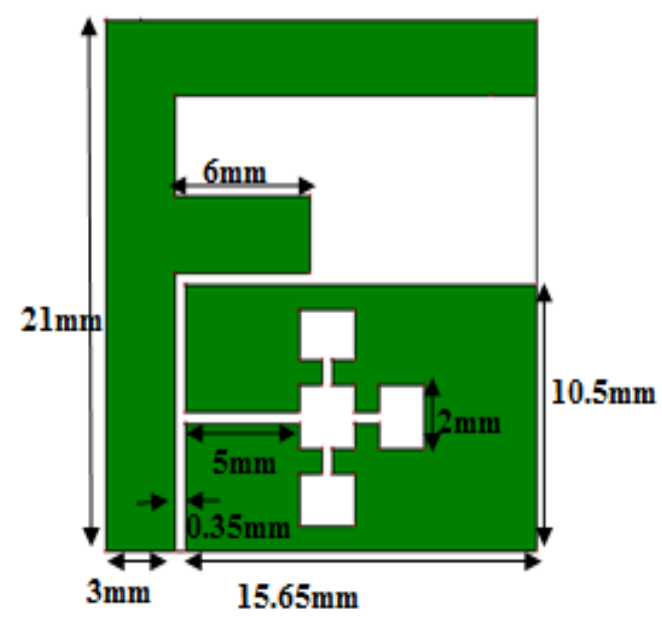

(a)

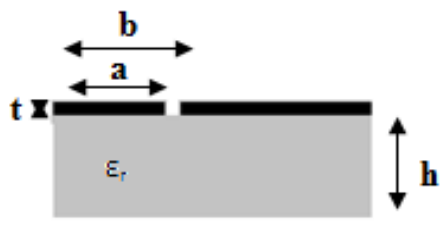

(b)

Figure 1. (a) Geometry of proposed ACS fed monopole Antenna (b) Cross section antenna

For the desired resonant frequency guided wavelength $\lambda_{g}$ is given by

$\lambda_{g}=c / \sqrt{\varepsilon_{e f f}} f$

The design equations $[13,14]$ for the perfect matching of impedance are given below

$$
Z_{o}=\frac{60 \pi}{\sqrt{\varepsilon_{\text {eff }}}} \frac{K(k)}{K\left(k^{1}\right)}
$$


Where, from Figure.1 (b)

$$
\begin{aligned}
& k=a / b \quad \text { and } \frac{K(k)}{K\left(k^{1}\right)} \text { is the elliptical integral of first kind which is given by } \\
& k^{1}=\sqrt{1-k^{2}} \\
& \frac{K(k)}{K\left(k^{1}\right)}= \begin{cases}\frac{\pi}{\ln \frac{2\left(1+\sqrt{\left.k^{1}\right)}\right.}{\left(1-\sqrt{\left.k^{1}\right)}\right.}} & 0 \leq k \leq \frac{1}{\sqrt{2}} \\
\frac{1}{\pi \ln \frac{2(1+\sqrt{k)}}{(1-\sqrt{k)}}} & \frac{1}{\sqrt{2}} \leq k \leq 1\end{cases} \\
& \varepsilon_{\text {eff }}=\frac{\varepsilon_{r}+1}{2}
\end{aligned}
$$

\section{RESULTS AND DISCUSSIONS}

The radiation characteristics of compact dual band ACS fed antenna shown in Figure 2. The antenna shows the resonance at $3.4 \mathrm{GHz}$ with return loss of about $-25 \mathrm{~dB}$ bandwidth of $300 \mathrm{MHz}$ and, another resonance at $5.5 \mathrm{GHz}$ and with return loss about $-30 \mathrm{~dB}$ and impedance bandwidth of $1300 \mathrm{MHz}$ for WiMAX/WLAN applications. The Figure 3(a) shows the various iterations of DGS on ground plane of ACS fed antenna. The comparison of return loss characteristics of proposed antenna with different iterations of dumbbell shaped DGS are shown in Figure 3(b). From it is clear that proposed antenna gives optimum performance comparing with other defected iteration from which it is evolved.

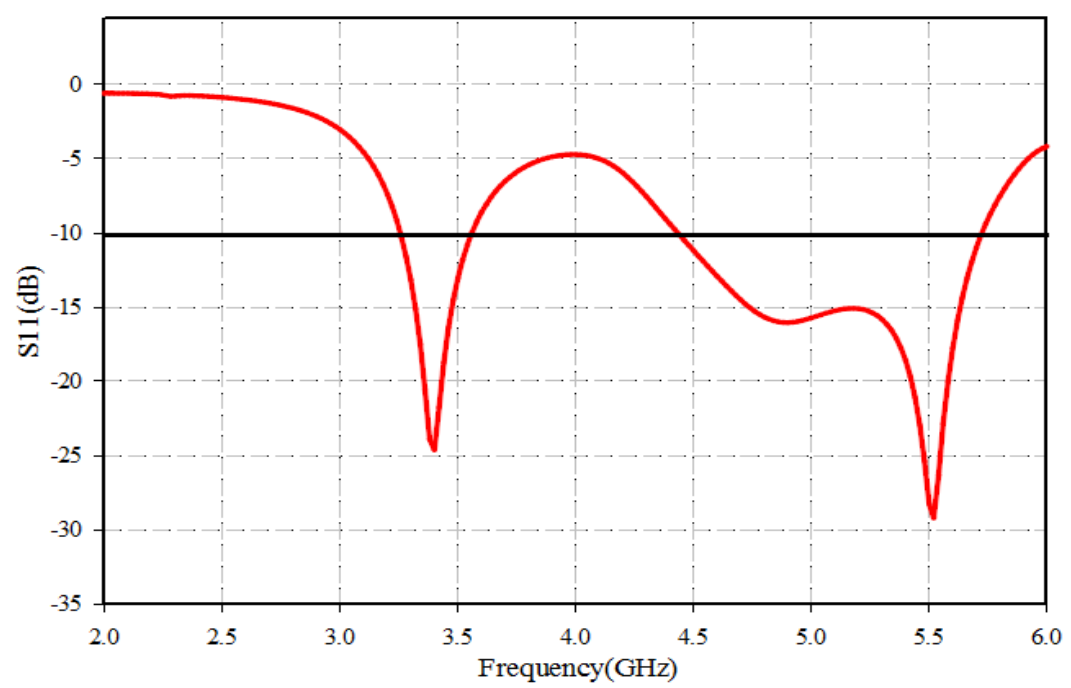

Figure 2. Return loss characteristics of proposed antenna 


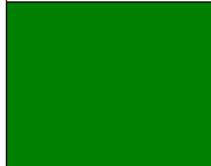

(i)

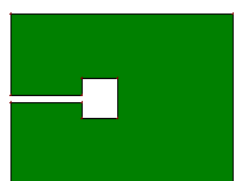

(ii)

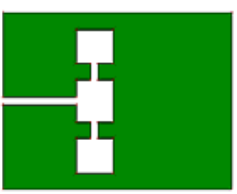

(iii)

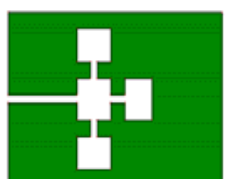

(iv) Proposed

(a)

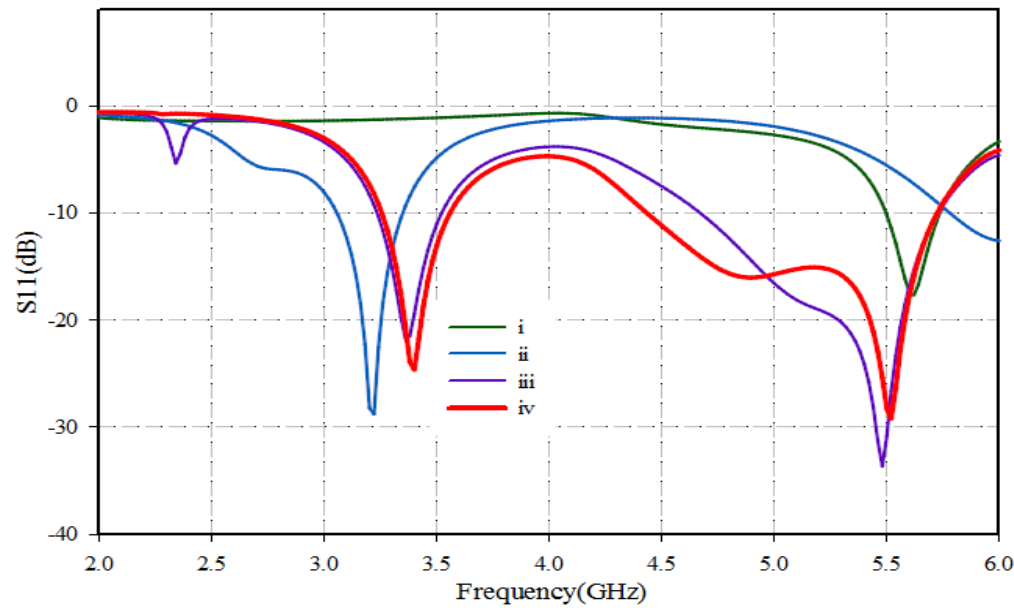

(b)

Figure 3. Various iterations of DGS; (a) Design evolution of ground plane with DGS, (b) Comparison of return loss characteristics for proposed antenna with different iterations of defects in the ground plane

Figure 4 shows the current distribution of proposed antenna with $\mathrm{F}$ shaped exciting stub and dumbbell shaped defected resonators. In figure 4(a) it is clear that current will perturb across $F$ shaped exciting stub on which causes the resonance around $3.4 \mathrm{GHz}$. In $4(\mathrm{~b})$ shows the disturbance in the current which is perturbed across the dumbbell defect in the lateral ground plane which contribute second resonance at $5.5 \mathrm{GHz}$. The resonances are useful for the present wireless communication standard such as WiMAX/IEEE 802.11a WLAN/HIPERLAN-2/RFID standards

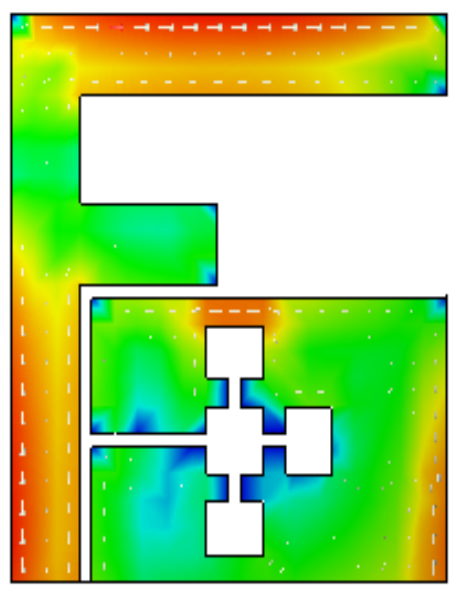

(a)

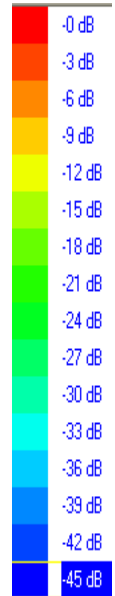

$4 \mathrm{~dB}$

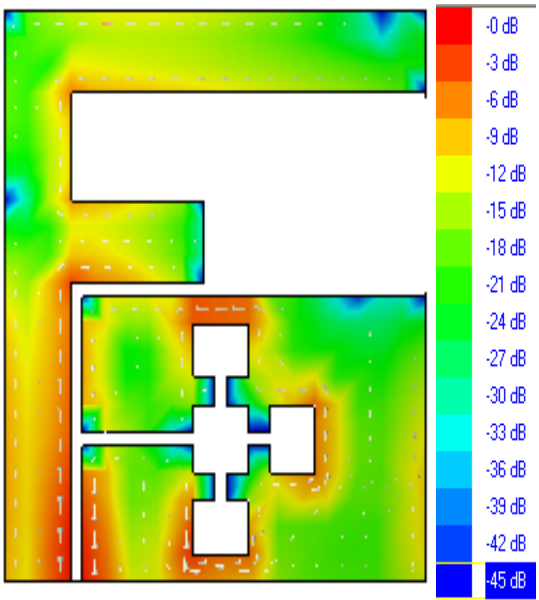

(b)

Figure 4. Current distribution of proposed antenna (a) $3.4 \mathrm{GHz}$ (b) $5.5 \mathrm{GHz}$ 
Table 1. Comparison of size and peak gain of proposed antenna with exsisting liturature

\begin{tabular}{cccc}
\hline Existing literatures & Peak Gain $(\mathrm{dBi})$ & Total size $\left(\mathrm{mm}^{3}\right)$ & Band \\
\hline Bo Li et al [4] & 1.4 & $35 \times 19 \times 1.6$ & dual \\
Chow.et.al [5] & 1.3 & $35 \times 15 \times 1.6$ & dual \\
Deepuet.al [7] & 2 & $28 \times 30 \times 1.6$ & dual \\
Yue Song et.al [8] & 1.5 & $15 \times 31 \times 1.6$ & dual \\
Ashkarali et. Al [9] & 1.81 & $37.5 \times 24.5$ & dual \\
Proposed Antenna & 3.8 & $21 \times 19 \times 1.6$ & dual \\
\hline
\end{tabular}

The table 1 shows the comparison of gain and overall area of proposed antenna with existing literatures. The proposed deign yield simulated peak gain is about $3.8 \mathrm{dBi}$ with dumbbell shaped defect on the lateral ground plane which is superior than other geometries in the existing literatures. Here it is clear that proposed antenna occupies only $21 \times 19 \times 1.6 \mathrm{~mm}^{3}$ which is very less than that of other possible variants in the lituratere. The defect using dumbbell also enhances the miaturaisation of proposed design.

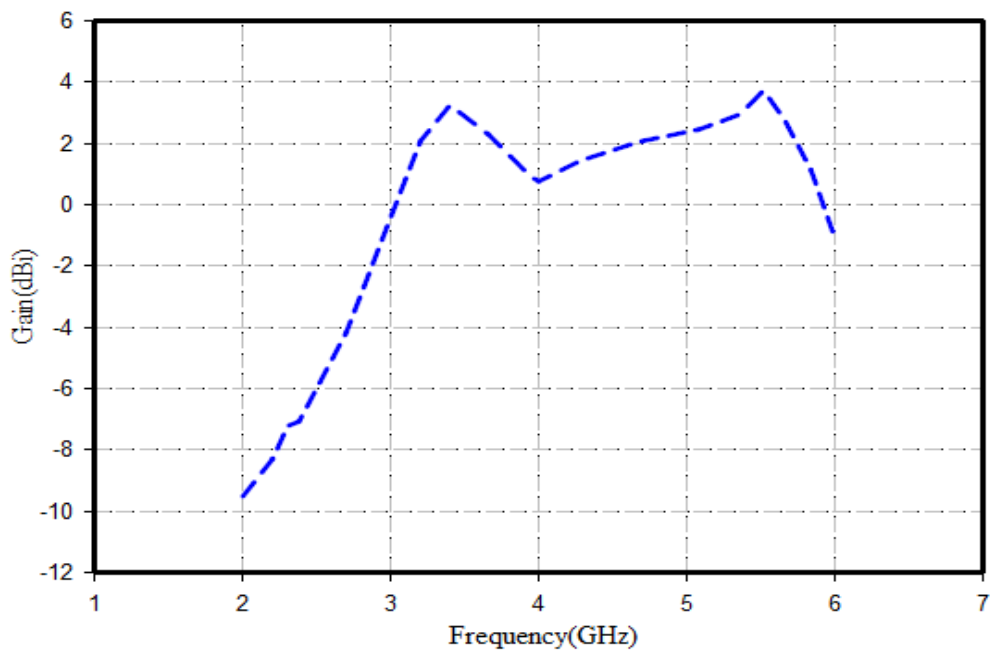

Figure.5 Gain Vs Frequency of proposed antenna

Figure 6 shows the simulated radiation patterns with Elevation and azimuthal plane at resonant frequencies by using Mentor Graphics IE3D software. The simulated radiation patterns of antenna in the Eplane (XZ-plane) and H-plane (YZ-plane) for two different frequencies $3.4 \mathrm{GHz}$ and 5.52GHz. The patterns and other curves are obtained at the time of simulation. We observed good radiation patterns by taking 20 cells per wavelength. Finally the antenna gain is calculated and displayed in Figure 5 the antenna gain is observed more than $3.4 \mathrm{dBi}$ at $3.4 \mathrm{GHz}$ owing to good return loss of about $-25 \mathrm{~dB}$, and gain of about $3.8 \mathrm{dBi}$ $5.5 \mathrm{GHz}$ which is sufficient for present and future wireless communication standards. 

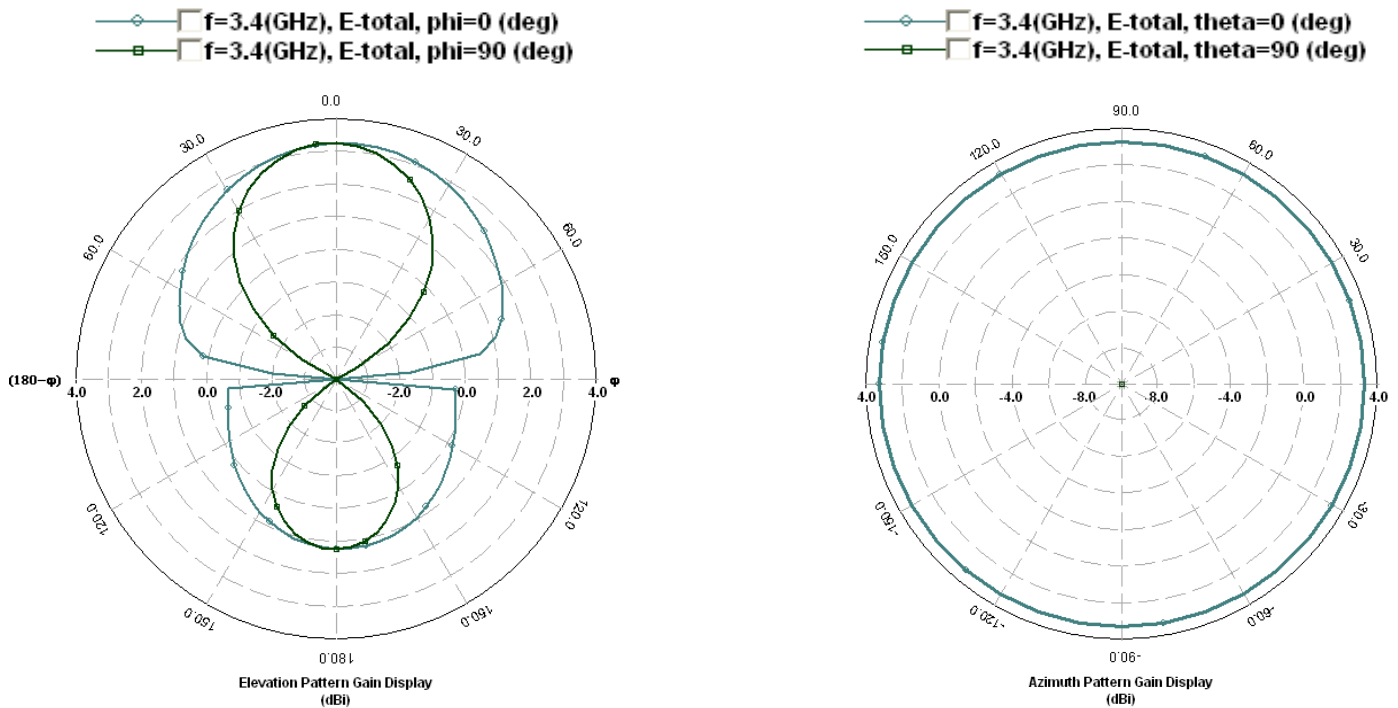

(a)
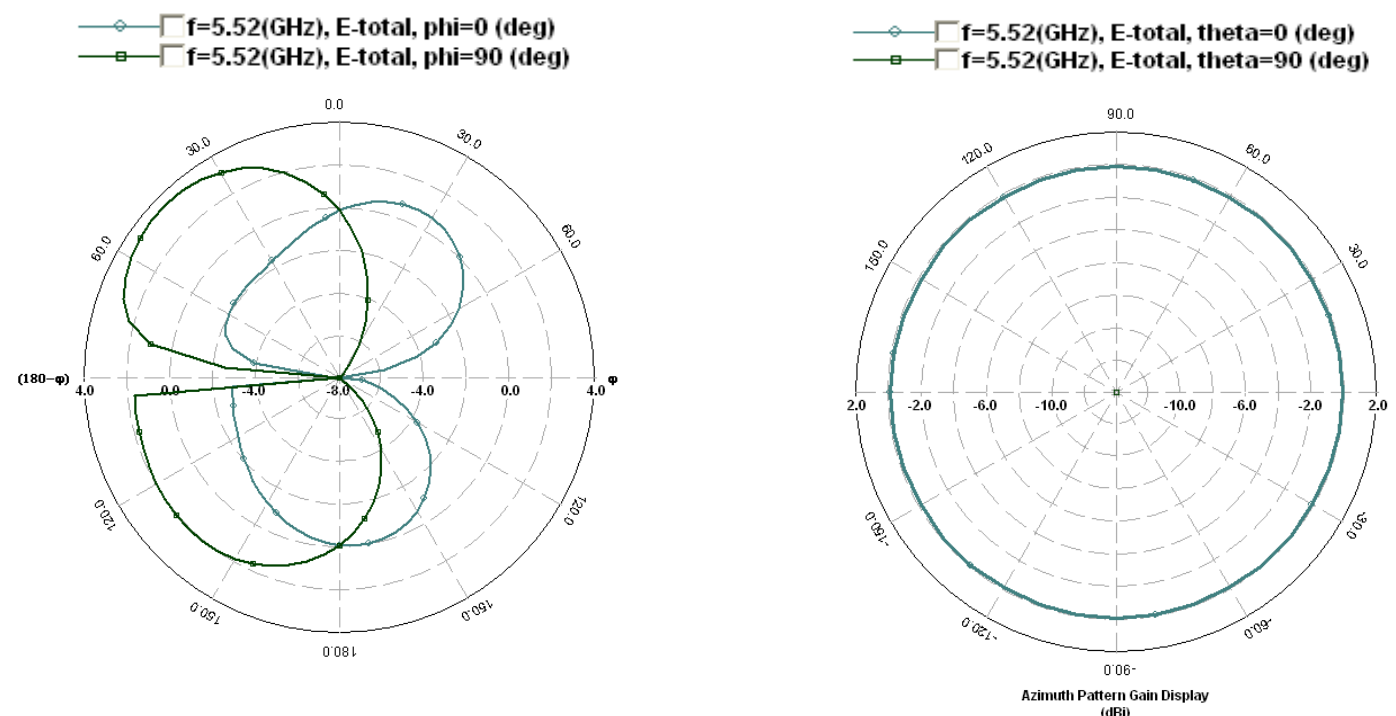

(b)

Figure 6. 2D Radiation patterns of proposed antenna (a) $3.4 \mathrm{GHz}$ (b) $5.52 \mathrm{GHz}$

\section{CONCLUSION}

A novel ACS fed dual band antenna for wireless applications is presented with a compact size of $21 \times 19 \times 1.6 \mathrm{~mm}^{3}$. The proposed antenna was analyzed by mentor graphics software IE3D. Due to F Shaped exciting strip and defected ground structure the proposed antenna exhibit average return loss of $(-25 \mathrm{~dB})$, good VSWR (around 1), better impedance matching at $50 \mathrm{Ohm}$ with ACS structure. Therefore, the proposed antenna is the suitable structure for WiMAX/WLAN and various wireless applications.

\section{ACKNOWLEDGEMENTS}

Authors are gratefully acknowledge University Grant Commission, New Delhi for the technical and financial support 


\section{REFERENCES}

[1] Z.N. Chen, Antennas for portable devices, Wiley, England, 2007: 1-52.

[2] J.Y. Jan and L.C. Tseng, Small planar monopole antenna with a shorted parasitic inverted-L wire for wireless communications in the 2.4-5.2, and 5.8- GHz bands, IEEE Trans Antennas Propag, 2004; 52: 1903-1905.

[3] Y.J. Cho, Y.S. Shin, and S.O. Park, Dual-band internal WLAN antenna for $2.4 / 5 \mathrm{GHz}$ laptop PC applications, Microwave Opt Technol Lett, 2006, 48: 2349-2354.

[4] Bo Li,Zehong Yan ,Tianling Zhang,Triple band Slot Antenna with U shaped open stub fed by asymmetric coplanar strip for WLAN/WiMAX Applications, progress in electromagnetic research letters 2013; 37: 123-131.

[5] Chow Yen Desmond Sim, Dual band CPW fed monopole antenna with asymmetrical ground plane for bandwidth enhancement, Microwave and Opt Technol Lett, 2008; 50(11): 3001-3004.

[6] V. Deepu, R.K. Raj, M. Joseph, M.N. Suma, and P. Mohanan, Compact asymmetric coplanar strip fed monopole antenna for multiband application, IEEE Trans Antennas Propag, 2007; 55: 2351-2357.

[7] Deepu V., R. Sujith, S. Mridula, C.K. Aanandan, K. Vasudevan, and P. Mohanan, ACS fed printed F-shaped uniplanar antenna for dual band WLAN applications, Microwave Optical Technology Letters, 2009; 51(5); 1852 56.

[8] P. Askarali, S. Sreenath, R. Sujith, R. Dinesh, D.D. Krishna, and C.K. Anandan, A compact asymmetric coplanar strip fed dual Band Antenna for DCS/WLAN application Microwave Optical. Technology Letters, 2012; 54(4): 1087-89.

[9] Yue Song, Yong Chang Jiao, Compact slot antenna fed by asymmetric coplanar strip for 2.4/5 GHz WLAN operations Microwave and Opt Technol Lett, 2008; 50(12): 3080-3083.

[10] Abdelhak Ferchichi, Gharsallah Ali. A Novel Small Sierpenski Antenna, International Journal of Electrical and Computer Engineering.2013; 3(4): 436-440.

[11] Chaouki Guesmi, Abdelhak Ferchichi, Ali Gharsallah, A Modified Fractal Bow Tie Antenna for an RFID Reader, International Journal of Electrical and Computer Engineering, 2014; 3(4): 441-446.

[12] L.H. Weng, Y.C. Guo, X.W. Shi, and X.Q. Chen. An overview of defected ground structure, Progress in electrommagnetics researech. 2008; 7(1): 173-189.

[13] Simons R.N., Coplanar Waveguide Circuits, Components an Systems, John Wiley \& Sons, NY, 2004.

[14] R. Garg, P. Bhartia, and I. Bahl, Microstrip antenna design hand book, 1st ed., Artech House, MA, 2001, pp. 794 795.

[15] K.A. Ansal, T. Shanmuganantham, ACS-Fed Wide Band Antenna with L-Shaped Ground Plane for 5.5GHz WLAN Application, Progress In Electromagnetic Research Letters, 2014, 49: 59-64.

[16] K.A. Ansal, T. Shanmuganantham, ACPW-Fed Planar Dual Band Antenna with DGS and DMS for WiMAX and WLAN Application, international journal of microwave and optical technology, 2014; 9(3): 221-226.

\section{BIOGRAPHIES OF AUTHORS}

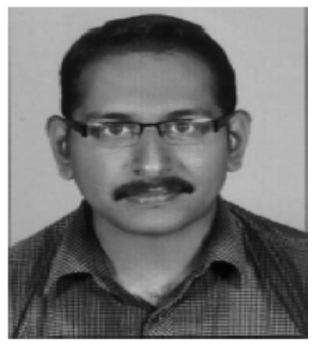

Ansal K.A. received B.Tech Degree in electronics and communication Engineering from Mahatma Gandhi university, Kottayam, Kerala in 2007, M.E degree in communication systems from Anna University Chennai, India in 2011.He is currently Working towards Ph.D. degree at school of engineering and Technology, Pondicheery university (Central university) puducherry, India. He has authored 15 journals and conference papers. His research interest include Microwave and millimetre wave antennas, planar antennas with DGS and EBG and Mobile Base station antennas. He is a member of IEEE, IAENG and IEICE

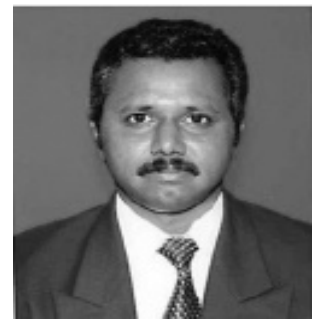

T. Shanmuganantham received B.E. degree in Electronics and Communication Engineering from University of Madras, M.E. degree in Communication Systems from Madurai Kamaraj University and Ph.D. (Gold Medal) in the area of Antennas from National Institute of Technology, Tiruchirappalli, India under the guidance of Dr. S. Raghavan. He has 15 years of teaching experience in various reputed Engineering colleges such as SSN College of Engineering, National Institute of Technology and Science. Presently he is working as Assistant Professor in. Department of Electronics Engineering, School of Engineering \& Technology, Pondicherry University, Pondicherry. His research interest includes Microwave/MillimeterWave Circuits and Devices, Antennas. He has published 130 research papers in various national and International level Journals and Conferences. He is a member in IEEE, Life Member in IETE, Institution of Engineers, CSI, Society of EMC, OSI, ILA, ISI, and ISTE 